Check for updates

The BMJ

Cite this as: BMJ 2021;372:n124 http://dx.doi.org/10.1136/bmj.n124 Published: 14 January 2021

\section{Covid-19: Past infection provides $83 \%$ protection for five months but may not stop transmission, study finds}

\section{Elisabeth Mahase}

People who have previously been infected with covid-19 are likely to be protected against reinfection for several months, but could still carry the virus in their nose and throat and transmit it to others, according to a study which regularly tested thousands of healthcare workers. ${ }^{1}$

The preprint reported interim results from Public Health England's Siren study between 18 June and 24 November 2020. During that period, researchers detected 44 potential reinfections and 409 new infections. This equated to an $83 \%$ rate of protection from reinfection, which appeared to last for at least for five months from first becoming sick.

The research team warned, however, that early evidence from the next stage of the study suggested that some people who are themselves protected by antibodies still carry high levels of virus and could continue to infect others.

Susan Hopkins, Public Health England senior medical advisor and Siren study lead, said, "We now know that most of those who have had the virus, and developed antibodies, are protected from reinfection, but this is not total and we do not yet know how long protection lasts. Crucially, we believe people may still be able to pass the virus on."

NHS staff who volunteered for the study were assigned to either the positive cohort (antibody positive or prior polymerase chain reaction (PCR) antibody test positive) or negative cohort (antibody negative, not previously known to be PCR antibody positive). They attended regular PCR and antibody testing (every two to four weeks) and completed fortnightly questionnaires on symptoms and exposures.

Between 18 June and 9 November 2020, 20787 staff (84\% female, 88\% white, median age 45.9) were included in this analysis, of whom 6614 (32\%) were assigned to the positive cohort and $14173(68 \%)$ to the negative cohort.

By 24 November 2020, 409 new infections were detected in the negative cohort, of whom 249 (79\%) were symptomatic at infection. Meanwhile, 40 (12\%) were asymptomatic and 28 (9\%) did not complete a questionnaire at the time of their symptoms.

The researchers detected 44 potential reinfections in the positive cohort, 15 (34\%) of which were symptomatic. Some 42 were defined as possible (two positive PCR samples 90 or more days apart, or a new PCR positive at least four weeks after an antibody positive result), and two were defined as probable (additionally required quantitative serological data or supportive viral genomic data). This compares with 318 new PCR positive infections (249 symptomatic) and 94 antibody seroconversions in the negative cohort.

The researchers calculated that adjusted odds ratio was 0.17 for all reinfections ( $95 \%$ confidence interval 0.13 to 0.24 ) compared with PCR confirmed primary infections, equating to $83 \%$ protection. The median interval between primary infection and reinfection was over 160 days.

When looking at only symptomatic cases supported by positive PCR results, previous infection reduced the odds of reinfection by at least 90\% (adjusted odds ratio 0.06 with 95\% CI 0.03 to 0.09).

The study team stressed that these results give no insight into the effects of vaccines or the new more transmissible variant in the UK, because of the time period analysed. These factors will be considered in later stages of analysis.

1 Hall V, Foulkes S, Charlett A, et al. Do antibody positive healthcare workers have lower SARS-CoV-2 infection rates than antibody negative healthcare workers? Large multi-centre prospective cohort study (the SIREN study), England: June to November 2020. 14 January 2021. 